\title{
ANTICONVULSANT ACTIVITY OF CYCLOPENTANO AMINO ACIDS
}

\author{
ROBERT ZAND ${ }^{1}$ AND IVAN IZQUIERDO ${ }^{2}$ \\ 'Biophysics Research Division, Institute of Science and Technology and Department of \\ Biological Chemistry \\ The University of Michigan \\ Ann Arbor, Michigan 48109 \\ ${ }^{2}$ Department of Biological Chemistry, Institute Biociences Universidade Federal Do Rio \\ Grande Do Sul \\ Porto Alegre, Brazil
}

Accepted May 28, 1979

\begin{abstract}
The hypothesis that certain amino acid analogues possessing a five-membered ring structure or amino acid analogues that can be viewed as fragments derived from such a ring would have anticonvulsant activity was proposed and tested. The compounds 1-aminocyclopentane carboxylic acid, 1-amino-3-methylcyclopentane carboxylic acid, 3 -aminotetrahydrothiophene carboxylic acid, and $\alpha$-aminoisobutyric acid were found to protect rats against seizures in the maximal electroshock test but offered no protection against metrazol- (pentylenetetrazol) induced seizures in mice. The structural feature of this class of anticonvulsants that allows for hydrophobic interactions at the receptor site is considered to be a major physical factor necessary in promoting the activity of this class of anticonvulsants.
\end{abstract}

\section{INTRODUCTION}

In previous investigations we have shown that a number of bicyclic amino acid analogues can effectively discriminate between the $A$ and $L$ transport systems in both eukaryotic and prokaryotic cells (1-3). In addition, we found that a number of these amino acid analogues can selectively elevate or depress the endogenous amino acid pool in rat brain (4) and that one of the bicyclic analogues can function as a competitive inhibitor of several branched-chain aminoacylsynthetases (5). Reports by other investigators $(6,7)$ have suggested that the endogenous brain amino acid pool has a 
participatory role in the pathogenesis of epilepsy. It has also been suggested that transient changes in brain tissue amino acid concentrations may occur during seizure activity $(8,9)$. An additional factor supporting the involvement of certain amino acids in the epileptic condition is that amino acid analysis of focal and surrounding regions of eleptogenic brain reveals that the levels of GABA, aspartic acid, glutamic acid, alanine, and taurine are often reduced below normal in eleptogenic foci and the level of glycine is frequently elevated (10). Not only have the amino acids GABA, glutamic acid, and taurine been used as anticonvulsant agents in the control of some forms of epilepsy that were induced in laboratory animals (11-13), but also taurine has been used as an antiepileptic in humans (14). The most widely used anticonvulsant, diphenylhydantoin, reportedly decreases the endogenous levels of glutamic acid and increases the concentrations of glutamine and GABA in brain (15).

Structural considerations of anticonvulsant compounds have led to the generalization that a large number of these compounds have geometries dominated by a five- or six-membered ring in their skeletal structure (16). It is also known that the excitatory or inhibitory properties of certain linear amino acids are potentiated if the linear structure is replaced by a ring structure (16). These various considerations suggested that the amino acid analogues that had been synthesized for our previous studies (Table I) should be screened for their potential anticonvulsant activity. This study reports our findings on the effectiveness of the four amino acid analogues depicted in Fig. 1, as anticonvulsant agents in the maximal electroshock test in rats and the metrazol test in mice.

TABLE I

1-Aminocyclopentane carboxylic acid

1-Aminocyclohexane carboxylic acid

1-Aminocycloheptane carboxylic acid

1-Aminocyclooctane carboxylic acid

2-Aminobicyclo $(2,2,1)$ heptane-2-carboxylic

acid

2-Aminobicyclo(3,2,1)octane-2-carboxylic acid

1-Amino-3-methylcyclopentane carboxylic

acid

3-Aminotetrahydrothiophene-3-carboxylic acid

$\alpha$-Aminoisobutyric acid 


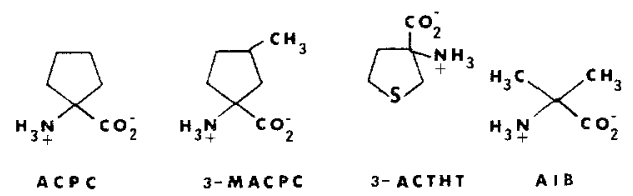

FIG. 1. Structures of the anticonvulsant amino acid analogues and their abbreviated name designations.

\section{EXPERIMENTAL PROCEDURE}

The amino acid analogues were synthesized and purified as described previously (4). The compounds 1-aminocyclopentane carboxylic acid (ACPC) and $\alpha$-aminoisobutyric acid (AIB) were dissolved in physiological saline while 3-methyl-1-aminocyclopentane carboxylic acid (3-MACPC) and 3-amino-3-carboxyl tetrahydrothiophene (3-ACTHT) were dispersed in physiological saline by the addition of 4-6 drops of Tween 80 . The test solutions were then adjusted to the desired concentration and administered intraperitoneally. Control animals received identical volumes of solution of the same osmolarity but lacking the amino acid analogue.

Maximal Electroshock Seizure Test (17). Wistar rats weighing 160-240 g were subjected to electroshock-induced convulsions by passing an a.c. current of $150 \mathrm{~mA}$ for $0.2 \mathrm{sec}$ between both eyeballs. This caused the immediate development of a full fledged convulsive syndrome consisting of a clonic phase followed by a hindlimb extension phase with an average duration of $12.9 \pm 1.2 \mathrm{sec}$. The time to reach the peak effect of the i.p.-administered analogue was determined at a dose of $80 \mathrm{mg} / \mathrm{kg}$ for ACPC and $50 \mathrm{mg} / \mathrm{kg}$ for the other three amino acids. Two groups of eight to ten rats each were tested by each compound. The animals were subjected to a convulsive current at $0.5,2,4,6$, and $8 \mathrm{hr}$ after injection for one group and $1,3,5$ and $7 \mathrm{hr}$ after injection for the second group. The time to achieve a peak effect and the duration of maximum anticonvulsant activity were then determined from the results of these experiments.

Metrazol (Pentylenetetrazol) Seizure Test (17). Convulsions were elicited in male Swiss albino mice weighing $20-35 \mathrm{~g}$ by the subcutaneous injection of $85 \mathrm{mg} / \mathrm{kg}$ of metrazol. Dosages of amino acid analogue ranged from $40 \mathrm{mg} / \mathrm{kg}$ to $320 \mathrm{mg} / \mathrm{kg}$ for ACPC and from $100 \mathrm{mg} / \mathrm{kg}$ to $200 \mathrm{mg} / \mathrm{kg}$ for the other amino acids.

\section{RESULTS}

In the maximal electroshock seizure test of Swinyard (17), ACPC at a dose of $80 \mathrm{mg} / \mathrm{kg}$ afforded protection to 11 of 12 animals in the test group at $5 \mathrm{hr}$ after injection. The other analogues were tested at a dose of 50 $\mathrm{mg} / \mathrm{kg}$ because of the much lower solubility of both 3-MACPC and 3ACTHT. These compounds, however, afforded protection at $4 \mathrm{hr}$ after injection rather than $5 \mathrm{hr}$ as with ACPC. The results of these experiments (Tables II and III) show a dose-response relationship at $5 \mathrm{hr}$ after injection for $\mathrm{ACPC}$ and at $4 \mathrm{hr}$ for the other amino acids. The $\mathrm{ED}_{50}$ for each amino 
TABLE II

Time to Achieve Maximum Protection by Amino ACid Analogue in THE MAXimal Electroshock Test ${ }^{a}$

\begin{tabular}{ccccccccc}
\hline $\mathrm{hr}$ & ACPC & $\begin{array}{c}80 \mathrm{mg} / \mathrm{kg} \\
(\%)\end{array}$ & MACPC & $\begin{array}{c}50 \mathrm{mg} / \mathrm{kg} \\
(\%)\end{array}$ & AIB & $\begin{array}{c}50 \mathrm{mg} / \mathrm{kg} \\
(\%)\end{array}$ & 3 -ACTHT & $\begin{array}{c}50 \mathrm{mg} / \mathrm{kg} \\
(\%)\end{array}$ \\
\hline 0.5 & $1 / 8$ & 15 & $2 / 8$ & 25 & $0 / 8$ & 0 & $0 / 8$ & 0 \\
1.0 & $2 / 8$ & 25 & $3 / 8$ & 38 & $1 / 8$ & 13 & $3 / 8$ & 38 \\
2.0 & $5 / 8$ & 62 & $3 / 8$ & 38 & $4 / 8$ & 50 & $4 / 8$ & 50 \\
3.0 & $5 / 8$ & 62 & $5 / 8$ & 62 & $3 / 8$ & 38 & $4 / 8$ & 50 \\
4.0 & $6 / 8$ & 75 & $7 / 8$ & 88 & $4 / 8$ & 50 & $4 / 8$ & 50 \\
5.0 & $11 / 12$ & 92 & $4 / 8$ & 50 & $4 / 8$ & 50 & $4 / 8$ & 50 \\
6.0 & $4 / 8$ & 50 & $3 / 8$ & 38 & $3 / 8$ & 38 & $4 / 8$ & 50 \\
7.0 & $3 / 8$ & 38 & $1 / 8$ & 13 & $2 / 8$ & 25 & $2 / 8$ & 25 \\
\hline
\end{tabular}

${ }^{a}$ The number of animals protected in a group and the percentage protected at the indicated amino acid dose as a function of time.

TABLE III

DOSE-RESPONSE RELATIONSHIP OF AMINO ACID ANALOGUES ${ }^{a}$

\begin{tabular}{rrrrrrrrrr}
\hline $\mathrm{mg} / \mathrm{kg}$ & ACPC & $\%$ & AIB & $\%$ & MACPC & $\%$ & 3 -ACTHT & $\%$ & $\mathrm{mg} / \mathrm{kg}$ \\
\hline 20 & $2 / 10$ & 20 & $3 / 11$ & 27 & $6 / 14$ & 43 & $5 / 13$ & 38 & 25 \\
40 & $4 / 12$ & 33 & $10 / 15$ & 67 & $8 / 13$ & 69 & $4 / 10$ & 40 & 50 \\
80 & $7 / 12$ & 58 & $7 / 8$ & 88 & $10 / 12$ & 83 & $5 / 8$ & 63 & 100 \\
160 & $11 / 12$ & 92 & & & & & & &
\end{tabular}

${ }^{a}$ Dose-response relationship at $5 \mathrm{hr}$ for ACPC and $4 \mathrm{hr}$ for the other amino acids expressed as the number of animals in a group protected and the percentage of the group protected in the maximal electroshock test.

acid was obtained by plotting the percentage of animals protected against the dose administered. For 3-MACPC the $\mathrm{ED}_{50}$ was $35 \mathrm{mg} / \mathrm{kg}$, for AIB the $\mathrm{ED}_{50}$ was $40 \mathrm{mg} / \mathrm{kg}$, for 3-ACTHT the $\mathrm{ED}_{50}$ was $60 \mathrm{mg} / \mathrm{kg}$, and for $\mathrm{ACPC}$ the $\mathrm{ED}_{50}$ was $66 \mathrm{mg} / \mathrm{kg}$.

The effectiveness of these compounds against electroshock-induced convulsions was not carried over to metrazol-induced convulsions. None of the compounds afforded any protection to mice against metrazol-induced seizures. At best, only one animal in a given test group survived. Even at an extreme dose of $1280 \mathrm{mg} / \mathrm{kg}$ of ACPC no protection against metrazol-induced seizures was observed. The results of these experiments are summarized in Table IV.

Although neural or other forms of toxicity were not specifically explored, no alterations of stance and gait or of the place reflex were ob- 
TABLE IV

EFFectiveness of Amino ACid Analogues Against Metrazol-INduCED CONVUlsions IN MiCE ${ }^{a}$

\begin{tabular}{rlrllllllr}
\hline $\mathrm{mg} / \mathrm{kg}$ & ACPC & $\%$ & $\mathrm{mg} / \mathrm{kg}$ & $\mathrm{AIB}$ & $\%$ & $\mathrm{MACPC}$ & $\%$ & 3 -ACTHT & $\%$ \\
\hline 40 & $0 / 9$ & 0 & 100 & $0 / 8$ & 0 & $1 / 8$ & 13 & $1 / 7$ & 14 \\
80 & $0 / 10$ & 0 & 200 & $0 / 8$ & 0 & $0 / 8$ & 0 & $0 / 2$ & 0 \\
160 & $0 / 10$ & 0 & & & & & & & \\
320 & $1 / 5$ & 20 & & & & & & & \\
1280 & $1 / 6$ & 19 & & & & & & & \\
\hline
\end{tabular}

${ }^{a}$ Metrazol test of analogue protection in Swiss Albino mice indicating the number of animals in the group that survived and the percent within the group that survived.

served at doses of $200 \mathrm{mg} / \mathrm{kg}$ for AIB, 3-MACPC, 3-ACTHT, and $320 \mathrm{mg} /$ $\mathrm{kg}$ of ACPC in rats or mice. Such alterations in motor or reflex behavior would have been indicative of neurotoxicity (17); however, the absence of such alterations does not exclude neurotoxic effects which may require an extended time period and long-term administration of the compound before becoming evident.

\section{DISCUSSION}

The anticonvulsive activity of the four amino acid analogues as measured by the maximal electroshock test clearly demonstrates that these compounds do provide a protective action. A ranking measure of their efficacy relative to other anticonvulsant agents can be made on the basis of their $\mathrm{ED}_{50}$ values. On this scale all four compounds would be ranked as less effective than cannabidiol (18), phenobarbital (19), or diphenylhydantoin (19) but well above oxazolidinedione compounds such as trimethadione or paramethadione (20). In contrast to the protective action of these amino acids in the maximal electroshock test, none of the compounds provided protection in mice, 4-5 hr after injection, against metrazol. However, Millichap (20) has pointed out that inactivity against metrazol is neither essential nor predictive of the efficacy of a compound in certain forms of epilepsy.

The structural features of the amino acid analogues that were used for predictive purposes of anticonvulsant activity, namely the presence of a five-membered ring, a carbonyl group, and an amino function, have been shown to be valid criteria for such compounds. The activity of AIB can be rationalized within this scheme if the molecule is viewed as being a 
fragment of a five-membered ring. The angle between the two methyl groups can reasonably be taken to be close to $109^{\circ}$. All of the straightand branched-chain amino acids have angles of this magnitude at the $\alpha$ carbon atom and its attached $s p^{3}$ hybridized bonds (21). The angle in ACPC and the other cyclic amino acids is $103-104^{\circ}(22,23)$. The bond lengths are essentially the same for all four compounds.

The mechanism by which any anticonvulsant agent acts is still unknown. The various anticonvulsants that have been studied often share some properties in common but are quite different with respect to other properties. For most anticonvulsants even the site of action has not been determined. Nevertheless, one feature that must be common to all of these agents is that there exists a receptor site in the tissue, even if different sites are needed for different compounds. These receptor sites must have certain conformational, geometric, and functional group requirements in order to recognize and bind the anticonvulsive agent. For those compounds that possess five-membered rings, a carbonyl group and an amino function, e.g., hydantoins and oxazolidinediones, the recognition mechanism must be such that the compounds used in the present investigation satisfy the requirements. In an aqueous milieu the primary binding mechanism is by hydrophobic interactions, and this feature is provided by the apolar hydrocarbon ring or the dimethyl groups of AIB. The attachment of apolar alkyl or aryl side chains to either the hydantoins, oxazolidinediones, succinimides, or the amino acid analogues would provide the additional sites for hydrophobic interaction. That hydrophobic interactions play a dominant role in the interaction of amino acids and transport proteins has previously been demonstrated (3). There is no reason for the interaction mechanism to change in the present system.

The results of this study also provide additional support for the hypothesis of five-membered ring geometry in certain classes of compounds as being associated with anticonvulsive activity.

\section{REFERENCES}

1. Christensen, H. N., Handlogten, M. E., Lam, I., Tager, H. S., and Zand, R. 1969. A bicyclic amino acid to improve discriminations among transport systems. $J$. Biol. Chem. 244:1510-1520.

2. Matthews, R. H., Sardovia, M., Lewis, N. J., and Zand, R. 1975. Biphasic kinetic plots and specific analogs distinguishing and describing amino acid transport sites in S37 ascites tumor cells. Biochim. Biophys. Acta 394:182-192.

3. MAtThews, R. H., and ZAND, R. 1977. Basis for substrate preference of amino acid transport system $\mathrm{L}$ over amino acid transport system A. Biochemistry 16:3820-3824. 
4. Zand, R., Sellinger, O. Z., Water, R., and Harris, R. 1974. $\alpha$-Aminocyclic and bicyclic alkane carboxylic acids: Differential effects on selected amino acids of rat brain cortex. J. Neurochem. 23:1201-1206.

5. ZAND, R., and WATER, R. 1977. Behavior of a bicyclic amino acid on in vitro protein synthesis. Tr. Am. Soc. Neurochem. 8:133.

6. Tapia, R., Rasentes, H., delamora, M. P., Ortega, B., and Massieu, G. H. 1967. Biochem. Pharmacol. 16:483-496.

7. SChmidt, R. P., and Wilder, B. J. 1968. Epilepsy, F. A. Davis Co., Philadelphia, pp. $109-112$.

8. Cremer, J. E. 1964. Amino acid metabolism in rat brain studied with ${ }^{14} \mathrm{C}$ labelled glucose. J. Neurochem. 11:165-185.

9. Namorski, S. R., Roberts, D. J., and Stewart, G. G. 1970. Some neurochemical aspects of pentamethylene-tetrazole convulsant activity in rat brain. $J$. Neurochem. 17:621-631.

10. Van Gelder N. M., Sherwin, A. L., and Rasmussen, T. 1972. Amino acid content of eleptogenic human brain: Focal vs. surrounding regions. Brain Res. 40:385-393.

11. HAWKINS, Jr., J. E., and SARETT, L. H. 1957. On the efficacy of asparagine, glutamine, $\alpha$-aminobutyric acid and 2-pyrolidone in preventing chemically induced seizures in mice. Clin. Chim. Acta 2:481-484.

12. POND, D. A., and POND, M. H. 1961. Glutamic acid and its salts in petit mal epilepsy. J. Ment. Sci. 97:663-673.

13. Van Gelder, N. M., Koyama, I., and Jasper, H. H. 1977. Taurine treatment of spontaneous chronic epilepsy in a cat. Epilepsia 18:45-53.

14. Van Gelder, N. M., Sherwin, A. L., SaCKs, C., and Andeman, F. 1975. Biochemical observations following administration of taurine to patients with epilepsy. Brain Res. 94:297-306.

15. WOODBuRY, D. M., and ESPLIN, D. W. 1959. Neuropharmacology and neurochemistry of anticonvulsant drugs. Proc. Assoc. Res. Nerv. Ment. Dis. 37:24.

16. Schmidt, R. P., and Wilder, B. J. 1968. Epilepsy, F. A. Davis Co., Philadelphia, pp. $142-168$.

17. SwInYARd, E. A. 1969. Laboratory evaluation of antiepileptic drugs. Epilepsia 10:107-119.

18. IzQuierdo, I., and TANnHAuSER, M. 1973. The effect of cannabidiol on maximal electroshock seizures in rats. J. Pharm. Pharmacol. 25:916.

19. WoOdBuRy, D. M. 1969. Role of pharmacological factors in the evaluation of anticonvulsant drugs. Epilepsia 10:121-144.

20. Mrllichap, J. G. 1969. Relation of laboratory evaluation to clinical effectiveness of antiepileptic drugs. Epilepsia 10:315-328.

21. ICHIKAWA, T., and IITAKA, Y. 1969. The crystal structures of DL- $\alpha$ amino n-butyric acid. Acta Crystallog. B24:1488-1501.

22. Mallikarjuan, M., Chacko, K. K., and Zand, R. 1972. Crystal and molecular structure of 1-aminocyclopentane carboxylic acid monohydrate. J. Cryst. Mol. Struct. 2:53-66.

23. Carrell, H. L., Gallen, B., and Glusker, J. P. 1973. The crystal structure of an isomer of 1-amino-3-methylcyclopentane carboxylic acid. Acta Crystallog. B29:2580-2585. 